\title{
Integrated 3D density modelling and segmentation of the Dead Sea Transform
}

\author{
H.-J. Götze $\cdot$ R. El-Kelani $\cdot$ S. Schmidt • \\ M. Rybakov $\cdot$ M. Hassouneh $\cdot$ H.-J. Förster $\cdot$ \\ J. Ebbing · DESERT Group
}

Published online: 18 July 2006

(C) Springer-Verlag 2006

Int J Earth Sci (Geol Rundsch) (2006).

DOI 10.1007/s00531-006-0095-5

Unfortunately, in the original version of this article, the DESERT Group is missing in the list of authors.

The complete list of authors is shown here.

The online version of the original article can be found at http://dx.doi.org/10.1007/s00531-006-0095-5

H.-J. Götze $(\bowtie) \cdot S$. Schmidt

Institut für Geowissenschaften, Abtlg. Geophysik,

Christian-Albrechts-Universität zu Kiel, Otto-Hahn-Platz 1,

24118 Kiel, Germany

e-mail: hajo@geophysik.uni-kiel.de

R. El-Kelani

An-Najah University, Nablus, Palestine

M. Rybakov

Geophysical Institute of Israel, Holon, Israel

M. Hassouneh

Natural Resources Authority, Amman, Jordan

H.-J. Förster

GeoForschungsZentrum, Potsdam, Germany

J. Ebbing

Norges Geologiske Unders $\varnothing$ kelse, 7491 Trondheim, Norway 